\title{
Teachers' Understanding-Check Practices and Learners' Following Orientations in EFL Classroom Interaction: A Conversation Analytic Study
}

\author{
Sedigheh Karimpour \\ University of Mazandaran, Iran \\ Baqer Yaqubi \\ University of Mazandaran, Iran
}

\section{Introduction}

Teachers' questioning practice as one of the typical and fundamental interactional tools in L2 teaching and learning dominates classroom discourse, a practice which constitutes one of the principal ways in which teachers employ questions in order to guide cognitive and linguistic development of their learners (Brock, 1986; Walsh, 2006). Much of L2 research on teacher questions so far has been quantitative studies focusing on identifying different question types and the role of such questions in language acquisition. While questions are present in instructional contexts, developing effective questioning strategies seems to be a challenging task for L2 teachers. Thus, the investigation of teacher questions seems essential to understand their effects on language learners' practice and also their education (Yaqubi \& Mozaffari, 2011).

In recent years, various attempts have been made by scholars and practitioners of the field to identify the nature of teachers' questioning practices in relation to learners' participation opportunities. These studies have dealt with issues including classification of question types (Long \& Sato, 1983), questioning strategies (understanding-check questions) (Waring, 2008), students' L2 production (Lynch, 1996; Richards \& Lockhart, 1996; Seliger \& Long, 1983) learners' preference orientations (Waring, 2012), to name only a few. More recently, teacher questions have been investigated from the perspective of how they might promote the modification of interaction and therefore learning (Gibbons, 2003; Lee, 2006; Kim, 2010; Warring, 2012). By focusing on nonstructural aspects of language use or interactional practices such as turn-taking, repair, and sequential organization, these studies and others seek to gain insight into how second language interaction 
unfolds in reality of classroom discourse. One such practice which is mostly underrepresented in teacher training texts as essential component of teacher talk is understanding-check practice. Since the importance of understanding-check questions as integral part of teacher talk is acknowledged in various research in applied linguistics (e.g., Richards \& Lockhart, 1996; Wajnryb, 1992 Ur, 1996;; Warring, 2012), the present study aims to produce an empirical account of how understanding-check questions are used in language classrooms, within which contexts they are mostly used and how they are oriented to by the EFL learners. The following section will synthesize the body of work on teacher questions which serve as a background to our current study.

\section{Literature Review}

During recent years, teacher questions, have received a considerable amount of scholarly attention in applied linguistics (e.g. Waring, 2012). One of the most prevalent distinctions with regard to categorizing teacher questions in the language classroom is Long and Sato's (1983) referential versus display questions. While referential questions request information unknown to the questioner, display questions on the other hand request known information from the learner. The study showed that there are more display questions present in classroom interaction than referential. The dominance of display questions in the language classrooms has been confirmed in Musumeci's study (1996) which concluded that not only teachers talk more than their learners in the class, they manage classroom talk through initiating the majority of their verbal exchanges by means of a question which are most often in the form of an explicit request for information (display questions) followed by the selection of a particular learner to respond. In the same way, Brock (1986) found that those ESL teachers who were trained to ask referential questions ask more of such questions and thus receive more extended learner responses as a result. Among these studies, some questioned effectiveness of display questions in prompting classroom interaction and language use. Also, Shomoossi's study (2004) showed that though the amount of classroom interaction caused by referential questions is much greater than that caused by displays, not all referential questions could create interaction.

To sum, most prior work on teacher questions in L2 pedagogy have largely focused on the distinction between display and referential questions and considered the effectiveness of these questions in creating a communicative language classroom (Waring, 2008). While the number of these studies in literacy research is significant, few have explored how understanding-check questions are treated by 
the learners during classroom interaction. The present study provides a fine-grained analysis of question-answer sequences in the EFL classroom interaction on the basis of sociocultural theory (SCT) and conversation analysis (CA) methodology in order to extend the existing literature on teacher questions by focusing on a previously unanalyzed type of question that is understanding-check question. Within the framework of SCT (Donato, 2000; Vygotsky, 1978; Wertsch, 1985), learning is conceptualized as participation rather than acquisition and learning opportunities are viewed to be opportunities for engagement in the target language discourse. Given this notion of participation as learning, an important contribution that conversation analysis can make to the study of SLA is to detail the instructional practices that either create or inhibit the opportunities for participation (Lerner, 1995; Waring, 2008) and, by extension, the opportunities for learning.

\section{Yes/No Questions and Preference Organizations}

Since the understanding-check questions to be analyzed in the present study all formatted as yes/no questions, previous research on yes/no questions is relevant to our current study. Prior conversation analytic work such as (Waring, 2012; Pomerantz, 1984) has generated important insights into the nature of yes/no questions and thus preference organizations. The conversation analytic concept of "preference" does not refer to psychological preference, but to a structural relationship between parts of the sequence. Preferred responses are those which align with the activity which the first pair part seeks to accomplish (Koshik, 2002). Dispreferred responses on the other hand, are those which do not align with this activity, e.g. disagreement, or rejection, or refusal. Preferred and dispreferred responses are often characterized by a contrasting set of features. Preferred responses are usually short, done without delay, and unmitigated. Dispreferred responses are often elaborated, delayed, and mitigated (Schegloff, 1988b, 1995b). "Yes/no" questions seem likely to be designed grammatically to prefer answers which embody one of the two alternatives, "yes" or "no" (Koshik, 2002; Raymond, 2000; Sacks, 1987 [1973]; Schegloff, 1995a).

In line with the findings by Quirk (1985), yes/no questions could be regarded as "conducive questions" i.e. questions which "indicate that speaker is predisposed to the kind of answer he has wanted or expected" (p.120). Bolinger (1957) relates conduciveness in yes/no questions both to elements of the question design and to what he calls the "assumption" of the speaker. Only negative question can be conducive. Koshik (2002) concluded that yes/no questions are used by teachers in second language writing conferences to convey negative assertions and, more 
specifically, to indicate what is problematic about the student's writing and to point out possible solutions. In sum, prior CA work has yielded important insights into the preference as well as functions of yes/no questions in a variety of contexts. In the present inquiry, we hope to extend these analytical themes by focusing more specifically on the function of a particular type of yes/no questions used by teachers in the second language classroom ie. understanding-check questions. Therefore, two research questions emerged from the present study.

\section{Research Purpose}

The study reported here adopts the emic approach to provide a fine-grained analysis of question-answer sequences in the EFL classroom interaction on the basis of sociocultural theory (SCT) and conversation analysis (CA) methodology. An important contribution that conversation analysis can make to the study of SLA is to detail the instructional practices that either create or inhibit the opportunities for participation (Lerner, 1995; Waring, 2008) and, by extension, the opportunities for learning. One such instructional practice concerns teacher questions and the following learners' orientations. Therefore, this study pays close attention to how EFL learners orient to understanding-check questions asked by teachers and the sequential contexts in which they are mostly used. Since there are few studies in literacy which delved into the specificity of how understanding-check questions are treated by the EFL learners in the details of classroom interaction, the study reported here adopted conversation analysis to extend the existing literature on teacher questions and more specifically on teachers' understanding-check questions.

\section{Research Questions}

1) In what sequential contexts EFL teachers tend to use understanding-check questions?

2) How understanding-check questions are oriented to by EFL learners?

\section{Method}

This study takes conversational analysis (CA) as its methodological framework. CA is a way of analyzing social interaction. The usefulness of CA as an analytical tool, especially in applied linguistics, has been discussed by many scholars (e.g. Kasper, 2009; Kasper \& Wagner, 2011; Long, 2007). The underlying perspective is 
that social contexts are not static but are constantly being formed by the participants through their use of language and the ways in which turn-taking, openings and closures, sequencing of acts, and so on are locally managed (Boyle, 2000). In this respect, CA approaches consider contexts as being mutually constructed between the participants. As with other CA studies, we first collected spoken data through audio and video recordings and then all lessons were transcribed in detail. The data for this study comprised video recordings of $6 \mathrm{EFL}$ teachers' classes and their 178 learners who will hereafter be referred to as the main participants of the study. The teachers let us videotape two of their sessions, for a total of twelve 90-minute lessons, totaling approximately 18 hours, a reasonable sample size on which to draw conclusions in the light of evidence from previous studies (Seedhouse, 2004). A total of twelve lessons and classroom observations were then used for data analysis.

As with the procedure to analyze the data, a line-by-line CA analysis of the entire collection was done which finally resulted in a few observations concerning teachers' understanding-checks. Based on the initial analysis of the data, all the instances of understanding-check questions were yes/no questions. Moreover, three major sequential environments emerge to feature the presence of understandingcheck questions in this study: (1) activity boundaries occasions (2) post-teacher instructions/explanation occasion and (3) within-activity occasion. Activity boundary is an occasion where a particular lesson segment is ending and moving to the next section. Post-explanation or post-instruction is an occasion where the teacher has already finished explaining a vocabulary item, a grammatical structure or the like, or just completed giving instructions for an upcoming activity (Waring, 2012). Finally, within activity is a juncture where the teacher is in the middle of the explanation or the activity and during the explanation or the activity s/he uses understanding-check questions.

In selecting extracts to be included in this study aside from ensuring that the full range of practices are represented based on the detailed CA analysis of the six cases, we also made an effort to include extracts from all six classes to provide some evidence that the practices were not unique to individual teachers or learners. In the remainder of this paper, we aim to describe how the understanding-check questions are oriented to by the participant learners as preferring no-problem in three different sequential contexts. This is at odds with the interactional purpose of such questions. 


\section{Results}

During the analysis of the data, some EFL teachers practiced understanding-check questions after completing an explanation. Post-explanation or -instruction is where the teacher has already finished explaining a vocabulary item, a grammatical item or just completed giving instructions for an upcoming activity. In this case, some of the responses used by the students after teachers' understanding-checks were in preferred format and some of the responses were in dispreferred format. The following extracts are taken from the data which aim to show the way learners orient to teachers' understanding-check questions.

\section{Micro Analysis of the Extracts Based on Preference Organizations}

\section{Post Instruction/Explanation Sequential Environment}

During the analysis of the data, some EFL teachers entered post-instruction context in which they practiced understanding-check questions. Post-explanation or instruction is an occasion where the teacher has already finished explaining a vocabulary item, a grammatical or just completed giving instructions for an upcoming activity. In this case, some of the responses used by the students after teachers' understanding-checks were in preferred format and some of the responses were in dispreferred format. The following extracts are taken from the data which aim to show the way learners orient to teachers' understanding-check questions.

Yes-Problem

Dispreferred Format

Extract 1 for analysis

$130 \mathbf{T}=\uparrow u s e \underline{\text { mo:::re }}$ or le::ss ${ }^{\circ}$ adjectives $^{\circ}$ that has.$>$ more syllables $<$ and don't end in... y,

131 ok:::?(...) Some adjective::s end in y::, ${ }^{\circ}$ for example ${ }^{\circ}$ what? Pretty ok:::?(...) $\underline{Y}$

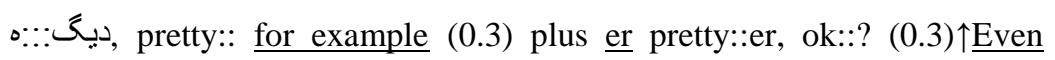
when the word or 
$134 \rightarrow$ add $\underline{\text { er }}$ in order to change $\mathrm{i}: \mathrm{t}$ to comparative form, oka::y(...) Did you $\mathrm{g}::: \mathrm{t}$ $\mathrm{i}::: \mathrm{t} ?(0.1)$

135 Oka:::y?(0.4) ${ }^{\circ}$ pretty:: ${ }^{\circ}=$

$136 \quad$ L2 $\quad={ }^{\circ}$ agai $:: \mathrm{n}^{\circ}=$

137 T =wha::t?

$138 \quad$ L2 again which ( )

139 T agai:::n?=

$140 \quad$ L2 =ye::s,[توضيح بدين]

In extract 1 the class has been practicing comparative adjectives. In lines (130-133) the teacher explains how comparative adjectives are made and he provides some examples for the learners. He starts his explanations with rising intonation in turn 130 (marked by $\uparrow$ ) and then he explains to the learners how adjectives with a few syllables will be changed to comparative adjectives by adding "er". During his explanations he repeatedly uses "OK?" as a form of understanding-check in lines 132, 133 and 134. Finally, in turn 134 the teacher used an understanding-check after a short pause indicated by (...). That "Ok?" in line 134 before teacher's understanding-check (Beach, 1993) as well as the understanding-check which he used in line 134 marks the completion of the instruction and signals postinstruction position of the interaction so far. Note that in line 136 L2's response is done with a delay marked by (0.4) indicated in line 135. L2's yes-problem response is produced with a (0.4) second delay as well as multiple signs of speech perturbation, such as a cutoff, lengthening, and pauses as well as an essentially unfinished turn-constructional unit indicated in line 136 (Sacks, Schegloff, \& Jefferson, 1974). In other words, learner's eventual yes-problem response in line 136 is preceded by a long, (0.4) second gap and further word used by the teacher (pretty) in line 135. As such, the learner treated yes-problem in dispreferred response to the teacher's understanding--check. After the pause of (0.4) in line 136, the learner asks the teacher to repeat his explanations. However, the teacher shows his misunderstanding by using "what?" immediately after learner's signal of problem (marked by latch $(=)$.

In this episode, the teacher used understanding-check questions in order to check learners' understanding of the instruction which he provided of how to make comparative adjectives. Although one of the learners signaled her problem to the teacher's understanding-check, her signal was with delay and mitigation. 
Therefore, it can be inferred that the learner treated his teacher's understandingcheck yes- problem in a dispreferred format.

\section{No-Problem}

\section{Preferred Format}

\section{Extract 2 for analysis}

$074 \mathbf{T}=\uparrow$ although $>$ they $<$ they mean negatively, somehow:: $\underline{\text { for example you }}$ sa::y that my::

075

076

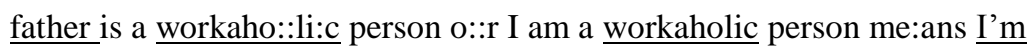
working a lot 个ye::s? >For long hours $<$ but somehow a ting يعنى يك ذره a ti:::ng of or a $(0.1)$ or (0.2) a ver:::y small negative $\uparrow$ meaning is going to... be extract from tha::t, ${ }^{\circ}$ so it's

079 đdifficult to do, > you're na::gging about that $<$, so you're nagging ...you're just (0.3)

080 going to ${ }^{\circ}, \underline{\text { listen }}$ ! when you $\underline{\text { say }}$ I'm workaholic, me::ans you fi:::nd it a little...bit

\section{L2 =yea: $\mathrm{h}=$}

082 T $\uparrow$ so:: workaholic i::s( ...)but some wo:::rds are neutral::1, for example the wo::rd (0.1)

083

strange

In extract 2, the teacher has been offering explanations in defining the meaning of word "workaholic" to the students in lines 074-080. The teacher begins the explanations by providing some examples in line 075 (marked by lengthened sound). During his explanations, he uses some words from their first language in line 076. In line 078, the teacher tries to catch all learners' attention by using "Listen" which is stressed (marked by underlining). Then the teacher in line 080 uses an understanding-check in order to check learners' comprehension of his previous explanations (Am I clear?). The use of understanding-check by the teacher in line 080 as well as the short pause or gap which emerges in line 080 (indicated by ...) mark completion of teacher's explanations and signals post- 
explanation sequential environment. Note that learners signal no-problem without any delay or mitigation in line 081 by answering "yeah" immediately after teacher's use of understanding-check. The immediate response of the students is indicated by latch $(=)$ in line 081 . Therefore, by delivering no-problem in preferred format i.e. without any delay or gap, learners treat teacher's understanding-check as preferring no-problem. Then in line 082, the teacher gives feedback to learner's answer to his understanding-check by using "so". It seems that the teacher is pleased with learner's signal of no-problem and wants to end the discussion about the meaning of word "workaholic".

To summarize, in this section the teacher provides explanations for the word's meaning. The learners responded teacher's understanding-check without any delay and mitigation. In other words, their response was in a preferred format. Thus, it can be inferred that the learners in this class treated no-problem in preferred format to teacher's understanding-check.

\section{No-Problem}

\section{Preferred Format}

\section{Extract 3 for analysis}

185 T $\uparrow$ ones, here, blue? Ones, blue gu::ys? It is using for plura::1, more than one, $>2345<$

186 one::s, one just one, >look look look $<$, somaye look, how much is this? Eeee you:: guy said eee which one? ...the blue one, the blue?one, look, how much are thes:::e?

188 $\uparrow$ Which ones? The answer is?(0.2) The black ones, it is plural, ok ok ,ok::., ببين شlack ones ${ }^{\circ}$, bu:::t if it is one, which

$190 \longrightarrow$ one? $\uparrow$ The black one... undersand? (0.2) ones, got i:::t? (0.3) no proble:::m?=

191 Ls =no:::=

$192 \mathbf{T} \quad=\uparrow I$ was waiting for you (0.2) so gu::ys, could you write them ple::::ase? 
In extract 3, the teacher explains the concepts of plurality and singularity to the learners and thus he provides some examples as shown in lines 185-190. In the middle of his explanation, the teacher uses some words in first language in lines 188 and 189 in order to help learners understand them better. The teacher tries to explain the difference between the plural nouns and singular nouns and he uses some numbers in line 185. To help his explanations be more understandable, the teacher asks some display questions to which he and students know the answers and then he answer them himself indicated by question marks in line 187 and 188 . The teacher's explanation comes to its completion in line 190, where a short pause (...) and (0.2) second gap emerges. This is followed by teacher's understandingchecks. Although in extract 2, the teacher used "Am I clear" as a form of understanding-check, in extract 3 the teacher used "no problem?" to check learner's understandings. Note that learners signal no-problem without any delay or mitigation in line 191 by answering " $n o$ " immediately after teacher's use of understanding-check which is indicated by latch $(=)$. Thus, by delivering noproblem in preferred format i.e. without any delay or gap, learners treat teacher's understanding-check as preferring no-problem. This is followed by teacher's confirmation of learners having no-problem which is indicated by his words "I was waiting for you" in line 192.

In this extract, the class was practicing the notion of plurality and singularity and the teacher was in the middle of providing some explanations for the students. Although the learners provided some responses for teacher's understanding-check, their responses were without any delay, mitigation or gap and it was immediately after teacher's understanding-check. Thus, in this extract the learners treated teacher's understanding-check in preferred format.

\section{Activity-boundary environment}

Some EFL teachers managed activity-boundary environment in which they practiced understanding-check questions. Activity-boundary is a juncture where a particular lesson segment is drawing to a close and transition to the next segment is relevant (Waring, 2012).In this respect, some of the responses used by the learners after each understanding-check were in preferred format and some of them occurred in dispreferred format. The following extracts are taken from the data to show how teachers use understanding-checks in activity-boundary environment and to show how they will be oriented to by the learners.

Yes-Problem

Dispreferred Format 


\section{Extract 4 for analysis}

541 T o:::h, $>$ I know I know $<,>$ no no no $<$, it's ma::de of, rubber, $(0.3)$ rubber, look

$542 \quad \uparrow$ plastic, rubbe:::rr, look $\uparrow$ have you ever seen a tyres of ca:::r? The tyre?=

543 Ls $\quad={ }^{\circ}$ ye: $: \mathrm{s}^{\circ}=$

$544 \mathbf{T}$ =tyre, of ca::r, a car has this, a tyre (0.2) made o:::f? Rubber, tyre:: made o:::f? Rubbe:::r,

$545 \longrightarrow>$ got $i:: t$ ? $<\underline{\text { Whose }}$ eraser is $\mathrm{i}::: \mathrm{t}$ ?

546 L3 ${ }^{\circ}$ mine $^{\circ}$

((The teacher gives her the rubber))

547 T thank you $^{\circ}$, rubbers (0.3) you know rubber::s, a ca:::r, you know tyres of ca::r,

((Some students speak quietly together))

548

$\begin{aligned} \longrightarrow & >\text { wait wait } \\ >\text { he::re<, } & \text { No Persian! a tyre made of rubbe:::rs, }\end{aligned}$

549 $>$ jot it down<, now, right now!

$550 \quad$ L8 $\quad$ it's, it's a:::?

$\mathbf{5 5 1} \mathbf{T}$ rubbe::r, yes rubber, it's made of rubber

In extract 4 , the class practices the quality and genus of different objects around the students and has just finished the last item. In this activity, each student is responsible to answer teacher's questions about what each of these objects is made of. In this respect, the teacher uses some examples (for example "tiers of the car" in lines 542-544). In line 545, the teacher uses his first understanding-check which marks completion of the activity and then he tries to give the objects back to the owners. This overall evaluative nature of the survey as well as teacher's attempt to give back the objects to the students marks completion of the activity and signals activity-boundary position of the interaction so far and the start of a new activity. When after the first understanding-check no student asked any question, the teacher decides to finish the activity. Therefore, when in line 548 he used understandingcheck after (0.2) second pause, he asked learners in line 549 to start a new activity of writing and answering the questions in their book. Note that, in turn 550 the 
learners' eventual yes-problem responses (line 547) is preceded by a long, (3.0) second gap and done with further within-turn delay (line 548) (Guys here, $>$ here $<$, > jot it down $<$, now, right now!). Thus, by delivering her yes-problem responses in a dispreferred format, L8 treats teacher's understanding-check as preferring no-problem.

In this section, the teacher used understanding-check in activity-boundary environment. The understanding-check which teacher used in extract 4 marked completion of an activity and signals activity boundary position. Just like postexplanation or post-instruction environment discussed before, the learners treated teacher's understanding-checks as preferring no-problem by acting in dispreferred format.

Yes-Problem

Preferred Format

Extract 5 for analysis

$412 \uparrow$ you don't pay attention to(..)this po::int, yo::u(..)will fall,over, yea::h? >It's hard

413 to<carry your, backpack,sorry $(0.3)$ “ $\uparrow$ don’t make your pa::ck too:: heavy at the

414 to::p, or bottom" there shoul::::d be a balance between (0.1) them, $\uparrow$ "it's best to kee::p,

415 the heaviest items, close to you:::r... ba::ck" near to you:::r...back, "yes(...)ha:::ve

$416-$ than,::t 's the only reason to do it<" (0.6) any question::n? (0.4) everything is

417

clear to you:::? (0.2) ye:::s?=

((L1 raised her hand))

418 L1 = $\uparrow$ excuse me::? >Bag? < bagging? ${ }^{\circ}$ Bagging? ${ }^{\circ}$ Mea::ns?

419 T what? Bala::nce?=

420 L1 =bury things, put someone in ${ }^{\circ}$ the ${ }^{\circ}=$

421 T =bury,aha, bury mea::ns to >put one thi:::ng under another thing $<$, you have burial 
ceremony, have you ever(...)to the graveya::rd, I mean, cemeter::y? You put $(0.1)$

423

you buried the body, (0.2) bury=

424 L1 >and balance<, ${ }^{\circ}$ balance mean ${ }^{\circ}=$

$425 \mathbf{T}$ =situation in which 2 opposing, forces, ${ }^{\circ} \mathrm{I}$ mean ${ }^{\circ}$ eee have or are given the $\underline{\text { same }}$

power, ok:::? they are in a balance, ok:::? we ${ }^{\circ}$ say $^{\circ}$

In extract 5, the class reads a passage. In lines 412-416, the teacher explains the meanings of the sentences and how they should be understood in each of the contexts of the reading. During her explanations, the teacher uses "yea::h?" in lengthened form in order to check learner's understandings and in order to follow the sentences. Then in turn 416, the teacher uses 2 understanding-checks one after another with (0.4) seconds gap between them. The (0.6) second gap which emerges before teacher's understanding-check in line 416 marks completion of the activity by the teachers and signals that the teacher is going to start a new activity. Note that in line 418 one of the students (L1) raised her hand in order to ask a question immediately after teacher's understanding-check (indicated by latch $=$ ). In lines 418 and 420, the student signals that she could not understand the meaning of word "bury" which the teacher explained before (during reading the paragraph). In this respect, L1's response is done without any delay or hesitation (indicated by =). In other words, the learner treated yes-problem in preferred format i.e. without any pause or mitigation. When in line 421 the teacher provides more explanations for the meaning of the word "bury", L1 asks the teacher to explain another word's meaning ("balance") in line 424.

In this section, the teacher and the students were about to finish a reading activity of their book. When the teacher aimed to change the activity, she used an understanding-check and immediately after this, one of the students (L1) decided to ask a question without any delay or pause. Unlike previous examples, in this extract the learners signaled their yes-problem in preferred format.

\section{No-Problem}

\section{Preferred Format}

\section{Extract 6 for analysis}

070 T $\uparrow$ necessary, ok::? let me::: make an example for both, (0.6) prohibition, refers to 
071 个prohibition a::nd(...)for example, $(0.2)$ he(...)mu::st not,watch, that movie, ok:::?

072

when you use must not, >it mea:::ns that $<$, he is not allowed, to watch, ok:::? now $\underline{\text { movie, }}$ ok? \\ here(...)her::e? He is not(..)prohibited, ha:::? He can watch the movie, but it is $\underline{\text { not }}$ \\ 075 necessary for him, ok::? aaa understand mehdi:? (0.2) he has a choice here, he can \\ 076 watch but it is not necessary for hi::m, yea:::h? But here(...)he is()no::t ${ }^{\circ}$ allowed ${ }^{\circ}$, \\ 077 understa:::nd?= \\ 078 L1 =ye::s= \\ $079 \mathbf{T}=$ ok:: $(0.33)$ what page are we a:::re?}

In this extract, the class practices the use of different necessity modals such as "must", "have to" and "has to" in different examples written by the teacher on the board. The class is about to finish the activity. The teacher tries to finish the activity by explaining the examples once more. The last word in line 076 "allowed" is in lowered voice and comprises the end of the activity. Moreover, 2 short pauses indicated by (...) in line 076 and teacher's use of understanding-check in line 077 signals activity-boundary position of the interaction so far. The teacher launches an understanding-check question in line 077. Note that, teacher's understanding-check is followed by learners" "yes" in line 078. In other words, learners signal no-problem without any delay by answering "yes" immediately after teacher's use of understanding-check which is indicated by latch $(=)$ in line 078 . Therefore, by delivering no-problem in preferred format i.e. without any delay or gap, learners treat teacher's understanding-check as preferring no-problem. The teacher then accepts the no-problem response and proceeds to move on to the homework segment of the lesson (line 079).

In this section, the class practiced use of some necessity modals written by the teacher as an example on the board. The understanding-check which teacher used in this extract marked completion of an activity and signals activity-boundary environment. Although in extract 5 learners signaled yes-problem in preferred format, in extract 6 learners signaled no-problem in preferred format. In other 
words, in this extract learners treated teacher's understanding-check as preferring no-problem.

\section{Within-Activity environment}

Apart from activity-boundary and post-explanation environments, one of the participant teachers entered within-activity occasion in which she practiced understanding-check question. Within-activity is a juncture where the teacher is in the middle of explanation and activity and during the explanation s/he uses understanding-check questions. It is observed that students signal no-problem without any delay, mitigation or hesitation even in within-activity occasion. Therefore, the following extract, taken from that particular teacher's class shows the way she uses understanding-check question in this sequential environment and how the understanding-check used by that teacher will be treated by her students in preferred or dispreferred format.

No-Problem

Preferred Format

Extract 7 for analysis

284 T $\uparrow$ yea::h, here the word ones was used to refer to shoes, so ${ }^{\circ}$ it's ${ }^{\circ}$ an it's a pronoun:::n,

285 so prepare for modest clothing, eee >what about Egypt?< Summe:::r

286 time is ho:t in Egypt, so pack light clothing but be sure to bring wa:::rm clothing

$287 \rightarrow$ that is also ${ }^{\circ}$ mode:::st ${ }^{\circ}(\ldots)$ it's clear, isn't i::t?=

288 Ls =ye::s $(0.2)$

289 T $\uparrow$ "warm weather clothing, if you visit a mo::sque (0.3) shoes are definitely out of the

290 question, >out of the question $<$ mea::ns? Not plausible or not allo::wed, ok:::? جاى

مجاز نيست ,بحث نيست ${ }^{\circ}$ shorts $^{\circ}$ are not allowed o::r (0.2) out of question::n, or out of 
question, (0.5) for both me::n and women, in masques women should wea:::r a

longer ski::rts (0.3) and a head covering, usually a scarf, and >the upper part of their

arms< should be covered by slee::ves, آستين ok:::? Sleeves (0.2) the upper part of their

a::rms should be:: covered b:y slee:::ves for touri::ng other wo::nderful si::ghts or

${ }^{\circ}$ historical places $^{\circ}(0.2)$ causal and comfortable clothing is fine for bo:::th eee w men

and $>$ women $<$, >by wonderful sights $<$ we mean some excellent places, wonderful::1

sights, sights here mea:::ns eee اماكن ديدنى,

In extract 7 , the teacher reads a short story written in student's book and the class listens to teacher's explanations. In lines 284 and 285, the teacher tries to help learners understand the reference for each of the propositions mentioned in the reading. The teacher starts her explanations with rising intonation indicated by $(\uparrow)$ in line 284. It is in the middle of her explanations that she launches an understanding-check question in line 287 (it's clear, isn't it?). Although the teacher does not finish the activity of reading and explaining the story for the students, in the middle of her explanations she uses an understanding-check in order to check learners' understandings of her previous explanations. This is indicated in line 289 that the teacher continues reading the story and providing explanations for the sentences of the story. Moreover, the teacher uses the last word she explains in line 287 in lowered voice $\left({ }^{\circ}\right.$ modes $\left.t^{\circ}\right)$. Finally, the teacher's understanding-check emerges after a short pause indicated by (...) in line 287 . Note that in line 288 , the students respond to teacher's understanding-check without any delay or hesitation as indicated by a latch (=ye::s). Thus, by delivering no-problem in preferred format i.e. without any delay or gap (Church, 2008), learners treat teacher's understanding-check as preferring no-problem. Then in line 289, the teacher continues reading the story in order to explain the sentences to the learners.

In this extract, the class has been practicing an activity of reading a story included in their syllabus. When the teacher was in the middle of explanation, she launched an understanding-check in order to check learners' understandings of her previous explanations. In this respect, students in her class responded teacher's 
understanding-check without any delay or hesitation. In other words, students of this class treated no-problem in preferred format.

\section{Activity-Boundary environment Merged With Post-Instruction environment}

The distinction between activity boundary and post-teacher explanation or instruction might be blurred on occasion when the two environments merge, as in Extract 8 . The teacher has brought her instructions about comparative adjectives to completion (lines 161-163) after which he is about to switch the activity indicated in lines 164.

Yes-Problem

Dispreferred Format

Extract 8 for analysis

161 T 1 Tيف من قشنح تر ار كيف خواهرم است

162 L5 my bag i::s...pretty::er, tha::n, my ...>my sister's bag<

$163 \quad$ T $\longrightarrow$ my sister's bag $<$, can I sa:::y my bag's sister? (0.2) No::: (...) Got it?

$164 \longrightarrow$ No proble:m? so, >shut your books $<$

$(0.12)$

165 L3 قيد؟

166 T $\uparrow$ adjective not adverb, $>$ Look! Look $<$, these are adjecti:.:ves

167 ta:::11, sho:::rt (0.1) pretty::, expensive, these a::re? Adjective

In extract 8, the class practices the use of comparative adjectives in English. The teacher starts his explanations with rising intonation indicated with $(\uparrow)$. He provides some examples for comparative adjectives and how they should be formed. For example, in line 162 he talks about the adjective "pretty" and how it should be changed into "prettier". In line 163, he launched the last example and this is indicated by a short gap (0.2). Finally, in line 163 the teacher launches two understanding-checks after (0.2) second gap. The (0.2) gap in line 163 marks the end or completion of teacher's instruction. In line 164, the teacher aims to switch the activity; therefore, he asks the students to close their books which marks 
activity-boundary position. Note that in line 165 L3's response to teacher's understanding-check question is done with a delay marked by $(0.12)$. In other words, learner's eventual yes-problem response in line 165 is preceded by a long, (0.12) gap. As such, the learner treated yes-problem in dispreferred format to teacher's understanding-check.

In this section, the distinction between two sequential environments (activityboundary and post-instruction) seemed to be blurred. In other words, the teacher's explanations and instructions was about to finish that he planned to switch the activity. Consistent with earlier observations, learner's yes-problem response is launched after a long (0.12) second gap, thereby signaling her treatment of the understanding-check question as preferring no-problem.

\section{Discussion and Conclusion}

This article has tried to demonstrate how our participant learners oriented to the understanding-check questions used by their teachers as preferring no-problem, which is evidenced in their delivery of no-problem responses in the preferred format and yes-problem ones in the dispreferred format. Moreover, the sequential structuring of interaction showed that our participant EFL teachers tended to use understanding-check questions in three sequential contexts: activity-boundary context, post-instruction context and within-activity context.

Compared to the varied sequential contexts in which our participant teachers used understanding-check questions, the learners manifested some variability in orienting to such questions. As illustrated under Extract 1, after teacher's use of understanding-check, the learner signaled yes-problem, yet the signal was produced with a (0.4) second delay and multiple signs of speech perturbation, such as a cutoff, lengthening, and an essentially unfinished turn-constructional unit. Thus, by delivering yes-problem in dispreferred format, the learners treated teacher's understanding-check as preferring no-problem. However, in Extracts 2 and 3, learners signaled no-problem without any delay or mitigation immediately after teacher's use of understanding-check question. According to Levinson (1983), preferred responses are produced without any delay or hesitation and the action is stated directly or properly done. Therefore, through delivering no-problem in preferred format i.e. without any delay or gap, learners treated teacher's understanding-check as preferring no-problem. As mentioned earlier, three sequential contexts featured the current study. In this respect, while Extracts 1,2 and 3 illustrated how learners oriented to teachers' understanding-checks in postinstruction context, extracts 4,5 and 6 showed learners' orientations for noproblem in activity-boundary context. As illustrated in extract 4 , by delivering their 
yes-problem responses in a dispreferred format, learners again treated teacher's understanding-check question as preferring no-problem. In addition, the same type of preference organization exists in within-activity environment which is illustrated in Extract 7. As illustrated in Extract 7, the learners treated teachers' understanding-check questions as preferring no-problem through delivering the response in preferred format. In Extract 8, the two environments (post-instruction and activity-boundary) are merged in a way that the distinction between them seemed to be blurred. As with the examples illustrated before, the learners treated yes-problem in dispreferred format to teacher's understanding-check question. In sum, the overall detailed CA analysis of these 8 extracts showed that in all three sequential contexts which featured the current study, learners tended to signal noproblem responses following their teachers' understanding-check questions either by signaling their no-problem in preferred format or by signaling their yesproblem, with delay and mitigation, in disprefered format. To sum, the findings of this study are in line with those reported by Waring (2012).

As mentioned earlier, the extracts chosen for this study include instances from all twelve classes and represent the full range of practices surrounding the use of understanding-check questions in our data. Also it should be noted that what we are observing here is not an idiosyncratic phenomenon, at least not within this particular data set. Moreover, there is no basis for claiming that these findings are representative of learner orientations in all adult EFL classes elsewhere. According to pomerantz "It should be clear that conversation analysis is not achieving empirical generalization" (Pomerantz, 1990, p 233). When applied to the current study, this means that our findings are not generalizable as descriptions of what other learners in an adult EFL classes do, but they are generalizable as descriptions of what any other learner in an adult EFL class can do in orienting to teachers' understanding-check questions.

The findings of this study contribute to existing work on preference, yes-no questions, and in particular teacher questions. First, the findings complement the existing literature on the context-specific nature of preferences. Moreover, learner preference for no-problem may in part be accounted for by the participants' competence concerns. Second, by detailing the use of yes/no questions in performing understanding-check, the findings also extend the existing work on the functions of such type of questions. The findings also have implications for research into teacher questions and more specifically teachers' understandingcheck questions by extending the existing work on the use of understanding-check questions. In addition, the information about teachers' understanding-check questions and learners' orientations to such questions will help the teachers become aware of all the possibilities in deciding the appropriate interactional practices 
during interaction with learners. In other words, this study tried to provide the opportunities for the teachers to be aware of their practice of checking learners' understandings. Finally, the findings of this study contribute to the literature on teacher questions in second language pedagogy and teacher education.

\section{References and notes:}

Brock, C.A. (1986). The Effects of Referential Questions on ESL Classroom Discourse. TESOL Quarterly 20:47-5

Cabrera, M and Martinez, P. (2001), the Effects of Repetition, Comprehension Checks and Gestures on Primary School Children in EFL Situation, ELT journal. Vol: 55/3

Dalton-Puffer, C. and Smit, U. (eds.) (2007) Empirical perspectives on CLIL classroom discourse.(pp. 7-24). Frankfurt: Lang.

Donato, R. (2000) Sociocultural contributions to understanding the second language classroom, In J.P. Lantolf (ed.) Sociocultural Theory and Second Language Learning (pp. 25-40). Oxford University Press.

Ellis, R.(2008). The Study of second language acquisition. (2nd ed.). Oxford: Oxford University Press.

Foster,P and Ohta, A. (2005). Negotiation for meaning and peer assistance in second language Classrooms. Applied Linguistics. 26/3. 402-430

Gass, S. (1997). Input, interaction and the second language learner. Mahwah, N. J.: Lawrence Erlbaum.

Gibbons, P. (2003). Mediating language learning: Teacher interactions with ESL students in a content-based classroom. TESOL Quarterly, 37(2), 247-273.

Heritage, J., Robinson, J., Elliott, M., Beckett, M., \& Wilkes, M. (2007). Reducing patients' unmet concerns in primary care: The difference one word can make. Journal of General Internal Medicine, 22, 1429-1433.

Hutchby, I., \&Wooffitt( 1998). Conversation Analysis. Cambridge, England: Polity Press

Jefferson, G. (1983). Notes on some orderliness of overlap onset. Tilburg, Netherlands: Tilburg Papers in Language and Literature No. 28.

Johnson, K.E. 1995. Understanding communication in second language classrooms. New York NY: CUP.

Kasper, G. (2009). Locating cognition in second language interaction and learning: Inside the skull or in public view? International Review of Applied Linguistics, 47, 11-36.

Kasper, G., \& Wagner, J. (2011).A conversation analytic approach to second language acquisition. In D. Atkinson (Ed.), Alternative approaches to second language acquisition (pp. 117-142). New York, NY: Routledge.

Kim, Y. (2010). Scaffolding through questions in upper elementary ELL learning. Literacy Teaching and Learning, 15, 109-137.

Koshik, I. (2002). A conversation analytic study of yes/no questions which convey reversed polarity assertions. Journal of Pragmatics, 34, 1851-1877. 
Lee, Y.A. (2006). Respecifying display questions: Interactional resources for language teaching. TESOL Quarterly 40, no. 4: 691-713.

Long, M.(1983). Native speaker/non- native speaker conversation and the negotiation of meaning. Applied Linguistics, 4, 126-41.

Long, M. (2007). Problems in SLA. Mahwah, NJ: Lawrence Erlbaum.

Long, M. and Sato C.J. (1983). Classroom foreigner talk Discourse: forms and functions of teacher's questions in Seliger and M.H. Long (ed). Classroom-oriented research in second language acquisition. (PP.268 - 285) Rowley, MA: Newbury House

Musumeci, D. (1996). Teacher-learner negotiation in content-instruction: communication atcross-purposes. Applied Linguistics 17(3): 286-325

Raymond, G. (2003). Grammar and social organization: Yes/No interrogatives and the structure of responding. American Sociological Review, 68, 939-967.

Richards, J. C., \& Lockhart, C. (1996).Reflective teaching in second language classrooms. Cambridge, England: Cambridge University Press.

Psathas, G. (1995). Conversation analysis: The study of talk-in-interaction. Thousand Oaks, CA: Sage.

Sacks, H. (1987). On the preferences for agreement and contiguity in sequences in conversation. In G. Button \& J. R. E. Lee (eds.), Talk and social organization (pp. 54-69).Clevedon, England: Multilingual Matters.

Seedhouse, P. (2004). The interactional architecture of the language classroom: A conversation analysis Perspective. Blackwell Publishing: University of Michigan.

Shomoossi, N. (2004). The effect of teachers`questioning behavior on EFL Classroom interaction: A classroom research study. The Reading Matrix Vol. 4, No. 2, September ten Have, P. (2007). Doing conversation analysis. Thousand Oaks, CA: Sage.

Thompson, J. (1997). Training teachers to ask questions. ELT Journal, 51, 99-105.

Ur, P. (1996). A course in language teaching: Practice and theory. Cambridge: Cambridge University Press.

Wajnryb, R. (1992). Classroom observation tasks: A resource book for language teachers and trainers. Cambridge, England: Cambridge University Press.

Walsh, S. (2006). Investigating classroom discourse. Cambridge: Cambridge University Press

Walsh, S. (2013). Conversations as space for learning. International Journal of Applied linguistics, 2(2) : 1-20

Waring, H. Z. (2012). Any Questions?: Investigating the Role of Understanding-Checks in Language Classrooms. TESOL Quarterly. Vol. 0

Waring. H. Z. (2013). How was your weekend?: developing the interactional competence in managing routine inquiries. Language Awareness. Vol. 22, No. 1, 1-16

Wong, J., \& Waring, H. Z. (2010).Conversation analysis and second language pedagogy: A guide for ESL/ EFL teachers. New York: Routledge.

Wootton, A. J. (1989). Remarks on the methodology of conversation analysis. In D. Roger \& P.Bull (Eds.), Conversation: An interdisciplinary perspective (pp. 238- 258). Philadelphia, PA: Multilingual Matters. 
Yaqubi, B, \& Mozaffari, F. (2011). EFL teacher questions to scaffold learning process: A Conversation Analytic Study. The journal of Applied Linguistics. Vol 4, issue 1 


\section{Appendix}

\section{Transcription Notation}

Conversation Analysis Transcription Conventions (adapted from Jefferson, 1983):

(.) untimed perceptible pause within a turn

underline stress

CAPS very emphatic stress

$\uparrow \quad$ high pitch on word

. $\quad$ sentence-final falling intonation

? yes/ no question rising intonation

, phrase-final intonation (more to come)

: $\quad$ lengthened vowel sound (extra colons indicate greater lengthening)

$=\quad$ latch (direct onset or no space between two unites)

$\rightarrow \quad$ highlights point of analysis

[ ] overlapped talk; in order to reflect the simultaneous beginning and ending of the overlapped talk, sometimes extra spacing is used to spread out the utterance

${ }^{\circ}$ soft $^{\circ} \quad$ spoken softly/ decreased volume

$>\quad$ increased speed

( ) (empty parentheses) transcription impossible

(words) uncertain transcription

(3) silence; length given in second

\$words\$ spoken in a smiley voice

(( )) comments on background, skipped talk or nonverbal behavior

$\{(())$ words. $\}\{\}$ marks the beginning and ending of the simultaneous occurrence of the verbal/ silence and nonverbal; absence of \{\} means that the simultaneous occurrence applies to the entire turn.

L1: L2: etc., identified Learner

"words" words quoted, from a textbook for example 
Summary

\title{
Teachers' Understanding-Check Practices and Learners' Following Orientations in EFL Classroom Interaction: A Conversation Analytic Study
}

\author{
Sedigheh Karimpour \\ University of Mazandaran, Iran \\ Baqer Yaqubi \\ University of Mazandaran, Iran
}

Classroom discourse is typically dominated by question and answer routines in which teachers ask most of the questions, a practice constituting one of the principal ways in which they control the discourse and push learners to contribute to classroom interaction (Brock, 1986; Walsh, 2006). Most of previous research on teachers' questions mainly focused on identifying and discovering different question types which believed to be helpful in creating the opportunities for learners' interactions. Drawing on conversation analysis through adopting socio-cultural perspective, this study, however, aims to examine how EFL learners orient to the teachers' understanding-check questions in three sequential contexts (activity-boundary, post instruction and within-activity) which emerged in this study. Informed by the tenets of conversation analysis, we have observed, videotaped, and transcribed line-by-line 6 EFL teachers' naturally-occurring classroom interaction. Analyses of 8 episodes from the data suggest that learners seemingly orient to the understanding-check questions used by their teachers as preferring no-problem, which is marked in their orientations to show no-problem responses in the preferred format and yesproblem responses in the dispreferred format. The findings of this study have implications for teacher education.

Keywords: Classroom Interaction, Conversation Analysis, Understanding-Check Questions, Preference Organization 